\title{
Cardiologic Medical Evacuations in Burkina Faso: Contribution of Three Philanthropic Sponsors over a 10-Year Period
}

\author{
Koudougou Jonas Kologo,,2, Georges Rosario Christian Millogo',2, Georges Kinda, \\ Jean Baptiste Tougma ${ }^{4}$, Nobila Valentin Yaméogo ${ }^{1,2}$, Anna Thiam Tall1,2, Larissa Kagambéga², \\ Caleb Tindano ${ }^{2}$, Eulalie Lingani' ${ }^{2}$, Mireille Simo-Moyo² ${ }^{2}$, Relwendé Aristide Yaméogo ${ }^{5}$, \\ Andre Koudougou Samadoulougou, ${ }^{1,2}$, Patrice Zabsonré1,2

\footnotetext{
${ }^{1}$ University Department of Medical Science (UFR/SDS), University Ouaga I Professor Joseph KI-ZERBO, Ouagadougou, Burkina Faso

${ }^{2}$ Cardiology Department of Yalgado Ouédraogo Teaching Hospital, Ouagadougou, Burkina Faso

${ }^{3}$ Medical Pediatric Department of Charles de Gaulle Pediatric Teaching Hospital of Ouagadougou, Ouagadougou, Burkina Faso ${ }^{4}$ Cardiology Department of Souro Sanou Teaching Hospital of Bobo Dioulasso, Bobo Dioulasso, Burkina Faso

${ }^{5}$ Medical Department of Regional Health Center in Koudougou, Koudougou, Burkina Faso

Email: millogo_rosa@yahoo.fr
}

How to cite this paper: Kologo, K.J., Millogo, G.R.C., Kinda, G., Tougma, J.B., Yaméogo, N.V., Tall, A.T., Kagambéga, L., Tindano, C., Lingani, E., Simo-Moyo, M., Yaméogo, R.A., Samadoulougou, A.K. and Zabsonré, P. (2017) Cardiologic Medical Evacuations in Burkina Faso: Contribution of Three Philanthropic Sponsors over a 10Year Period. Open Access Library Journal, 4: e3380.

https://doi.org/10.4236/oalib.1103380

Received: May 18, 2017

Accepted: June 19, 2017

Published: June 22, 2017

Copyright $\odot 2017$ by authors and Open Access Library Inc.

This work is licensed under the Creative Commons Attribution International License (CC BY 4.0).

http://creativecommons.org/licenses/by/4.0/

\begin{abstract}
Introduction: This study aimed at describing the socio-economic, diagnostic, and progressive features of patients evacuated thanks to philanthropic sponsors. Patients and methods: all evacuated patients, contacted through the phone and interviewed, were included in the study. A questionnaire helped in collecting data which were analyzed through the software Epi-Info (version 7). Outcomes: A total of 63 patients out of 134 were included in the study among which there are 22 adults and 41 children. The sex-ratio was 1.30 . Patients living in Ouagadougou accounted for $79 \%$ of cases. The children's average age at evacuation was $3.58 \pm 3.86$ years against $27.52 \pm 12.54$ years for adults. Ventricular septal defects among children (58.53\%) and mitral valve diseases among adults $(72.72 \%)$ were the main diagnoses at the time of evacuation. The average fall was 47 months for children, and 54 months for adults in the post-operative period. $68 \%$ of adults had an income below 50,000 FCFA per month. The evacuation average cost was estimated at 21,083,000 FCFA per patient, corresponding to 2,825,122,000 FCA over 10 years. Each adult patient spent an average of 15,000 FCFA per month for the follow up, against 8725 FCFA for children. $16 \%$ of patients were lost of sight in the post-operative. Conclusion: Philanthropic sponsors significantly contribute to the management of cardiac patients, and their efforts should be supported by a better monitoring. Setting-up cardiac surgery and interventional cardiology in Burkina Faso are required to address these health shortcomings.
\end{abstract}




\section{Subject Areas}

Cardiology

\section{Keywords}

Evacuations, Cardiology, Congenital Heart Disease, Heart Surgery, Sponsorship, Burkina Faso

\section{Introduction}

The treatment of cardiovascular diseases implies a medical treatment in one hand and a surgical treatment in the cases of congenital heart diseases of children and valvular heart diseases on the other. This operation on patients is practiced abroad, mainly upon funding from Burkina state [1] or through sponsors [2], since that heart surgery is not effective in Burkina Faso. Considering this context, we have planned to draw up an overview of the contribution of three philanthropic sponsors as regards cardiologic medical evacuations in Burkina Faso.

This study aims at describing the socio-economic, diagnostic and progressive features of the patients evacuated thanks to philanthropic sponsors because of heart diseases over a ten year (10 years) period.

\section{Methodology}

We have conducted a cross-cutting and retrospective study over a ten-year period going from January 2005 to December 2014. The population of study was made-up of all the evacuated cardiac patients by three philanthropic sponsors existing in Ouagadougou in Burkina Faso. Two of these organizations were in charge of the medical evacuation of children below 18 years old and the third one was responsible for medical evacuation of adults. The inclusion criteria were the following: being evacuated for any cardiac disease and being interviewed by our research team at the Teaching Hospital Yalgado Ouédraogo, and at the Hospital St Camille of Ouagadougou. The non-interviewed patients but contacted through the phone were not taken into account as well as those who could not be reached by the phone. Data were collected through a questionnaire over a two month period from May 2015 to June 2015. We did select a number of variables for analysis, including age, gender, residence, education level, income level, patients' destination, reason for evacuation, length of stay, cost of treatment, health insurance, and existence of follow up. Data were analyzed though the software Epi-Info (version 7). We did obtain permission from the local ethics committee of Yalgado Ouédraogo University Hospital.

\section{Results}

The study included a total of 63 persons out of 134 who were evacuated because of a heart disease. There were 22 adults and 41 children; and sex ratio was esti- 
mated at 1.30. Patients living in the capital Ouagadougou accounted for $79 \%$. As for children, the average age related to evacuation was estimated at $3.58 \pm 3.86$ years and that of adults reached $27.52 \pm 12.54$ years. The patients evacuated were generally of low socio-economic status. Indeed, $68 \%$ of adult patients during evacuation had an income below 50,000 FCFA/month.

Countries of destination of the evacuated patients are represented as follows: $48 \%$ for France, $35 \%$ for Spain $(n=22)$, and $17 \%$ for the United States of America $(\mathrm{n}=11)$.

The main affections bringing about medical evacuation were the following: Ventricular septal defect (VSD) (25 cases), mitral insufficiency (MI) (16 cases), Patent ductus arteriosus (PDA) (12 cases), aortic insufficiency (AI) (9 cases), atrial septal defects (ASD) (9 cases), mitral stenosis (MS) (8 cases), pulmonary stenosis (PS) (8 cases), Tetralogy of Fallot (TOF) (6cases), tricuspid insufficiency (TI) ( 2 cases) and other congenital diseases ( 2 cases). A same given patient could have a combination of some of such diseases. VSD among children (58.53\%) and mitral heart valves diseases among adults $(72.2 \%)$ were the predominant diagnoses during evacuation.

The stay duration abroad ranged from one (01) to seven (07) months and $82 \%$ of patients $(n=52)$ had an average duration between one (01) and two (02) months. The evacuation average cost per child amounted to 21,083,000 FCFA based on the data provided by sponsors.

The average fall was 47 months for children and 54 months for adults on post-operative period. Ten patients interviewed (16\% of cases) were lost of sight after their medical evacuation with no medical and post-operative contact with their medical practitioner. Each adult patient could spend an average of 15,000 FCFA/month for his/her follow-up, against 8,758 FCFA for children.

\section{Discussion}

One of the constraints during our study was the lack of prior data about the actions of sponsors concerning cardiologic medical evacuations in Burkina and their scarcity in Africa [1]. Furthermore, the relatively low percentage of patients interviewed did not allow assessing accurately the actions of the three sponsors involved.

The epidemiologic features of our patients are described below. The average age upon children evacuation was $3.58 \pm 3.86$ years (children) and $27.52 \pm 12.54$ years (adults). This average age for children is inferior to the one reported by Goeh Akoue in Togo (5 years regarding congenital diseases) [3] and FourcadePauty in Congo (9 years) [4]. The average age in our study is close to the recommendations setting the optimal intervention period to at least three years regarding the Tolerated VSD [5], [6]. An early diagnosis of congenital diseases allowing a timely treatment can explain such an observation. Besides, most of our adult patients (77\% of cases) had a low socio-economic status with a monthly income below 50,000 FCFA and $63 \%$ of them were unemployed. The education level was also low with $16 \%$ of patients having a primary school level, and $59 \%$ of 
them had no formal education.

This observation about the socio-economic status remained approximately the same after the medical evacuation. Diarra in Mali and Zabsonré [1] [2] had different findings as they found a strong proportion of public civil servants among the beneficiaries of public medical evacuations respectively estimated at $70 \%$ and $41 \%$. Therefore, we can confirm that sponsors 'contribution is more profitable to the poor.

As for diagnosis, VSD were mainly the diseases giving way to medical evacuations among children. This corroborates data from Kinda in Burkina [7] and Ngouala in Sénégal [8] showing a predominance of VSD regarding congenital heart defect among children. In our study, the ultrasound diagnostic concordance between national operators and those from overseas was estimated at $93 \%$. This can be deemed satisfactory because of the lack of trans-esophageal echocardiography (TEE) in our medical procedure, which is likely to provide a more reliable diagnosis.

Our study noticed a delay in the treatment of patients. So, there is the need to work towards reducing these evacuation time limits to better treat our patients. Therapeutic treatment of patients entails a significant financial cost: an observation coming from Zabsonré in Burkina Faso and Diarra in Mali. Indeed, the evacuation related-average cost trebled the one reported by Diarra in Mali and was five times that of Béchir in Mauritania [9]. This cost was not significantly different regardless it was a child or adult patient. This could be explained by long stay durations, the need to accompany children during their travel abroad, and the more costly destinations observed by our study. However, the stay duration abroad was below the one reported by Pedrant in Switzerland [10]. These treatment costs are prohibitive for most of adults with a low socio-economic status. The contribution of sponsors is all the more appropriate as the affected patients, in most cases, did not have any health insurance for both the preoperative and post-operative period (3\% before and $8 \%$ after).

Following-up patients after the post-operative period came along with an increase in financial fees and brought about a considerable percentage of patients lost of sight. In developing countries, the increase of financial fees raises the sensitive problem related to the socio-professional reinsertion of patients operated because of cardiovascular diseases. A more general treatment including a financial support or aid meant for professional reinsertion is necessary for adult patients coming back from their medical evacuation. Soulié [11] underscores that this approach is also deemed necessary in developed countries. Financial problems experienced by adults could in one hand explain the significant number of the lost of sight. On the other hand, this can be due to a feeling of full recovery after the surgery particularly among children. This could make patients or parents believe that the need for a medical follow-up is no longer necessary. This high percentage of the patients lost of sight, calls upon the need for a better medical follow-up after the surgery.

This main limitation of the study is the lack of data from the ministry of 
health which would have allowed us to make comparison with data from the non-profits and make relevant comments. The second limitation is the lack of contact information for all patients. This in fact did not allow us to reach out to all patients who were evacuated through these non-profits. It also prevented us to give an estimate of mortality rate. The last major shortcoming

\section{Conclusion}

Cardiologic medical evacuations considerably contribute to the treatment of cardiovascular diseases in Burkina Faso. Philanthropic sponsors significantly help in implementing this therapeutic measure. However, the treatment related-cost is high and the need to better follow-up patients is imperative in the post-operative period. Considering these observations, it is compulsory to develop local departments of interventional cardiology and heart surgery in order to meet the medical needs of many patients. A combined effort between medical doctors, public health facilities and sponsors is desirable so that to set-up these local centers for the treatment of heart diseases requiring a surgery or interventional treatment.

\section{References}

[1] Zabsonré, P., Nébié-Ouédraogo, L.V.A., Niakara, A., Bagré, F.K. and Toguyeni, J.Y. (2004) Medical and Economic Characteristics of Medical Evacuations for Cardiovascular Diseases. Tropical Cardiology, 30, 56-58.

[2] Diarra, M.B., Ba, H.O., Sanogo, K.M., Diarra, A. and Touré, M.K. (2006) Cost of Cardiovascular Evacuations and Needs in Surgical and Interventional Treatment in Mali. Tropical Cardiology, 32, 66-68.

[3] Goeh Akue, E., Kenou, A., Ekoue-kouvahey, D. and Soussou, B.L. (2013) Medical Transfers of Togolese Children for Heart Surgery by the NGO “Terre des hommes", 60 Cases Collected from 1993 to 2003. Cardiologie Tropicale, 130, 1-10.

[4] Fourcade-Pauty, V., Moyen, G., Nkoua, J.L. and Nzingoula, S (1993) Medical Transfers of Congolese Children: Assessment of 2 Years of Collaboration with the "Chain of Hope". Médecine d'Afrique Noire, 40, 171-174.

[5] Feltes, T.F., Bacha, E., Beekman, R.H., et al. (2011) Indications for Cardiac Catheterization and Intervention in Pediatric Cardiac Disease. A Scientific Statement from the American Heart Association. Circulation, 123, 2607-2652. https://doi.org/10.1161/CIR.0b013e31821b1f10

[6] Jondeau, G. (2001) Cardiopathies congénitales. Fac. Médecine Paris Ouest Cardiol. URL. http://www.pifo.uvsq.fr/pedagogie/cardio/cardiocongenitales.pdf

[7] Kinda, G., Millogo, G.R.C., Koueta, F., Dao, L., Talbousouma, S., Cissé, H., et al. (2015) Congenital Heart Diseases: Epidemiological and Echocardiographic Features. 109 Cases at the Pediatric Teaching Hospital Charles de Gaulle. Pan African Medical Journal, 20, 81.

[8] Ngouala, G.A.B.B., Affangla, D.A., Leye, M. and Kane, A. (2015) Prevalence of Symptomatic Heart Diseases of Children at the Regional Hospital of Louga, Sénégal. Cardiovascular Journal of Africa, 26.

[9] Béchir, S.A. (2013) Evaluation of Medical Evacuations Expenses Abroad during the Period 2008-2011 (Memoire de master). Université de Nouakchott, Mauritanie.

[10] Pedrant, P., Grandjean, T., Leiggener, C., Iglisias, P. and Stoll, B. (2008) Reception 
and Surgery Operations in Switzerland of Children Coming from Developing Countries. Enseignement, Université de Genève.

[11] Soulie, D. (2014) Prise en charge des cardiopathies congénitales chez l'enfant au CHU de Toulouse. sur Communiqué de presse.

http://www.chu-toulouse.fr/-communiques-de-presse-annee-2014-\#art6060

Submit or recommend next manuscript to OALib Journal and we will provide best service for you:

- Publication frequency: Monthly

- 9 subject areas of science, technology and medicine

- Fair and rigorous peer-review system

- Fast publication process

- Article promotion in various social networking sites (LinkedIn, Facebook, Twitter, etc.)

- Maximum dissemination of your research work

Submit Your Paper Online: Click Here to Submit

Or Contact service@oalib.com 